\title{
GAIA Level 3 Maternal Death
}

National Cancer Institute

\section{Source}

National Cancer Institute. GAIA Level 3 Maternal Death. NCI Thesaurus. Code C127999.

GAIA Level 3 Maternal Death is defined by three criteria: first, the absence of level 1 or level 2 criteria for establishing diagnosis of pregnancy, and both the uncertainty of the individual's last menstrual period date and no documented clinical examination; second, death of the mother temporal to pregnancy, childbirth, or the postpartum period when exact timing of death is unknown; third, documentation of the maternal cause of death wherein one of the following requirements must be met: a) Direct: abortive outcome, hypertensive disorder, obstetric hemorrhage, pregnancy related infection, other obstetric complications, unanticipated complications; b) Indirect: non-obstetric complications; c) Death during pregnancy, childbirth, and the puerperium: other or coincidental; d) Unspecified: unknown or undetermined. 